\title{
APPLICATION OF LOGIT MODELS IN SOCIAL REHABILITATION. THE FAMILY IN CRISIS - REPORT FROM STUDIES.
}

\author{
BEATA MARIA NOWAK, PhD Associate Professor
}

\author{
Pedagogium Wyższa Szkoła Nauk Społecznych w Warszawie \\ 00-102 Warszawa, ul. Marszałkowska 115 \\ E-mail address: nowak.beata.maria@gmail.com
}

Keywords: statistical method, logit models, family in crisis, study

\begin{abstract}
The author of the article presents the results of own studies on the demand of families in complex crisis for social assistance and support. She proposes to use logit models, which enable to study large populations of different types of families in a short time, and to identify trends in the development of these phenomena and processes, which significantly affect their current and potential functioning. This method can be used in the diagnosis of other social and educational phenomena, especially those that are characterized by high dynamics and the complexity of sources of occurrence, and require fast social response - drawing up precise prognoses, designing coping strategies and their implementation. The author of the paper also indicates that logit models can provide an analytical basis enriching, and complementing methods of measurement already recognized and successfully applied in the methodology of social and education studies.
\end{abstract}

\section{INTRODUCTION}

In the area of European social activity ${ }^{1}$ a strong orientation at preventing and counteracting social phenomena and processes disabling the functioning of individuals and groups is observed today. The family, universally understood as a basic environment, and simultaneously the most important for proper human development, is covered by special care and protection in this regard.

In Poland, on the basis of statistical monitoring of social phenomena and processes, local and regional environmental initiatives are designed ${ }^{2}$, located in the area of prophylactics and prevention, as well as social activity focused on supporting individuals and groups at risk of marginalization and exclusion. However, there are serious shortcomings in the area of identifying, monitoring and forecasting the impact of negative social trends on the condition and functioning of family systems. This is somewhat due to the fact that the family community is extremely sensitive and difficult in direct research contact. Hence, a need arises for such methods and techniques that, taking into account the various sets of factors, would allow to estimate the probability of certain phenomena occurring in the future, and fast and efficient analysis of developmental trends of family systems.

These expectations are met by the statistical method presented in this paper, used in the context of social support and assistance of families in overcoming a complex crisis ${ }^{3}$, which is the result of the co-existence and/or overlapping of situations and problems of various foundations and character.

Logit models ${ }^{4}$ enable joint identification of the etiology of a crisis and the needs of families touched by it for assistance and social support. The empirically created vision of vulnerable spheres of functioning of family systems, drawn on the basis of the analysis of their

\footnotetext{
1 Both institutional: government and local government, and civic: non-governmental and voluntary.

2 Group and individual, as well as institutional and civic.

3 R.K. James, B.E. Gilliland, Strategie interwencji kryzysowej, PARPA, Warsaw 2009; M. Lis-Turlejska, Psychologiczne konsekwencje traumatycznego stresu - współczesne kierunki badań, „Nowiny Psychologiczne” 2000, no 2.

${ }^{4}$ Logit is a quotient logarithm of odds of adopting and failing to adopt the value 1 by the variable Yi (M. Gruszczyński, Modele i prognozy zmiennych jakościowych $w$ finansach $i$ bankowości, „Monografie i Opracowania SGH” 2001, no. 490. In this transformation, rather than the empirical probabilities defined in the interval [0;1], we obtain the clearly corresponding logit value (L) and, consequently, a logit model.
} 
socio-demographic configurations, may be the basis for starting social activities of prophylactic nature already at the stage of diagnosing negative trends and determining the directions and areas of intervention, therapeutic or social rehabilitation actions. This provides a chance for fast social reaction towards problems noted directly by families and undertaking a wide range of activities (including non-conventional, alternative or innovative), focused on inhibiting negative trends or enhancing the positive directions of their development.

\section{REPORT OF STUDIES}

\subsection{METHODOLOGICAL ASSUMPTIONS OF OWN STUDIES}

Many economic and social phenomena submitted to analysis and forecasting is qualitative, hence the variables that describe them are discrete variables ${ }^{5}$. This applies especially to any matters relating to the behavior of individuals, e.g. natural persons or institutions. The choice of every possible behavior possibility (making a certain life decision or choice of a given option of conduct) depends on various factors, which are explanatory variables in the presented analyses.

The subject of this study ${ }^{6}$ was the demand of families in a complex crisis ${ }^{7}$ for assistance from various social actors offering specific types of help and support.

The study involved 731 families leaders ${ }^{8}$ of a complete structure - natural, nuclear, nuclear extended (3-generational), with at least one child ${ }^{9}$. The primary group was assigned 381 leaders of problem families ${ }^{10}$, while the control group was assigned 350 leaders of problem-free families ${ }^{11}$. Leaders from both groups of families had to indicate whether they were planning to take advantage of an institution providing social support to individuals and families in crisis: social welfare centre (OPS), Psychological and Pedagogical Clinic (P-P Clinic), labor office (UP) and the Voluntary Service Centre $(\mathrm{CW})$.

As potential explanatory variables, three socio-demographic variables were adopted: environment of residence (rural area; small town; medium-sized city); age in years; education (primary; vocational; secondary; tertiary) and income (in thous. PLN). The basic elements characterizing the two studied groups were similar. In each of these, about $1 / 3$ of the respondents came from rural areas, small towns and medium-sized cities. In the studied groups there was a higher proportion of women (approx. 60\%) than men. In terms of education, family leaders with secondary and tertiary education dominated. Half of the leaders of problem families was under 42 years old. The average income per one person in the families managed by them amounted to 0.54 thousand PLN. While half of the leaders of problem-free families were under 39 years old, and the average income per 1 person in the families managed by them amounted to 0.80 thousand PLN ${ }^{12}$.

The models were estimated separately for problem families and problem-free families, and also, after merging the two sets, for the entire studied population. In the latter case, the set of potential explanatory variables was expanded by the variable problem - adopting a value of 1 for the problem family and a value of 0 for the problem-free family. In order to compare the estimation

\footnotetext{
${ }^{5}$ M. Kowerski, Prognozowanie zjawisk dyskretnych, [in:] E. Nowak (red.), Prognozowanie gospodarcze, AWP Placet, Warsaw 1988 and M. Kowerski, Assessment of the economic condition of small enterprises with logit micro-macro models, Conference on Human System Interaction, HSI08, WSiZ, IEEE Industrial Electronics Society, Kraków, 2008.

${ }^{6}$ More in: B.M. Nowak, Rodzina w kryzysie. Studium resocjalizacyjne, PWN, Warsaw 2011.

${ }^{7}$ The following sources of crisis were reported in the surveyed families: long-term unemployment, earning emigration of parents, social maladjustment of children and adolescents, criminality of adult family members, disability or chronic illness, sudden loss of a close relative, addiction.

${ }^{8}$ It has been assumed that the family leader is a strategic person for the functioning of the family, who was identified on the basis of an agreement between spouses. The study was participated by the person, who in their opinion was more decision-making in matters of the family's everyday life and had a real impact (including financial) on the formation of aspirations and family plans.

${ }^{9}$ Families were reached through professionals - people working in schools, social welfare centres, psychological and pedagogical clinics, educational institutions and non-governmental organizations.

${ }^{10}$ Problem families (not independent), unable to cope with overcoming developmental crises, declaring the presence of long-term, numerous and unsolved problems, and requiring external assistance

11 Problem-free families (independent), coping with crises without external assistance, currently not declaring problems and providing stability of family functioning in at least a three-year perspective.

12 The distribution of income has a strong right-hand skewness, while the kurtosis is close to normal distribution.
} 
results, models were estimated on all of the specified explanatory variables. The estimation procedure was also performed from the general to the particular, eliminating variables with statistically insignificant parameters at a significance level of 0.05 . To assess the quality of the obtained models, an analysis of the significance of parameters was applied with the use of the $t$ Student test, while an analysis of the significance of the whole set of explanatory variables occurring in the model was performed using the test of quotient reliability ( $\chi 2$ statistics). Assessments of adjusting the model to empirical data was performed using McFadden's pseudo R2 coefficient and calculable coefficient of determination (accuracy).

\subsection{STUDY RESULTS}

In the course of the study analyses, it was found that $74.3 \%$ of the leaders from problem families expected assistance from at least one of the aforementioned assistance-support institutions, and $51.1 \%$ from problem-free families. Leaders of problem families much more frequently expected the help of two or three institutions. In both study groups the highest demand for assistance from a Voluntary Service Centre (38.6\% from the control group and $65.9 \%$ from the primary group) was found, while the fewest people were interested in the offer the labor office (respectively: 14.6 and $21.5 \%$ ). This result points to the current problems of the surveyed families associated with ongoing unemployment (most leaders of problem families declared the use of unemployment benefits), or potential problems associated with the fear of losing a job in the future, or resulting from the occurrence of chronic disease or disability of family members. The surveyed leaders also reported needs associated with increased childcare and educational difficulties occurring presently or projected in the future (indications at P-P Clinics). A large number of needs reported at the same time by the leaders of families indicates the various problems coexisting in the surveyed families. $4.6 \%$ of all leaders of problem families expect assistance from all four institutions, while $9.0 \%$ of people from problem-free families expect the need to use their assistance in the future.

\subsubsection{MODELS OF DEMAND OF PROBLEM FAMILIES FOR INSTITUTIONAL ASSISTANCE}

Depending on the type of institution, different variables significantly discriminate the surveyed population of leaders of problem families, while the same factor may be, in the case of one institution, a stimulant for needing help, and a destimulant for another. This relationship was found using the $t$-Student test of the significance of differences of average values of specified variables, depending on the demand for institutional assistance. In the case of expecting the help of an OPS, the determinant is education, where the higher the education of the leaders of families, the more they show the need for assistance from this institution. With respect to the P-P Clinic, there are three variables that significantly discriminate the surveyed population: age and education - the younger and better-educated the family leader is, the greater the need for assistance from this institution; income - the higher the income of one person in the family, the greater the need for aid from a P-P Clinic. In the case of expecting assistance and support from a Volunteer Center, only the age variable was statistically significant, where the need for help from volunteers is greater with age. However, no statistically significant variables were found discriminating the need for assistance from a UP. A similar situation occurred in the case of the variable describing the need of problem families in general.

Despite the fact that in the estimated logit models of demand for assistance, depending on the institution, different sets of variables proved significant, some similarities (trends) can be identified:

1) In all estimated models, the parameter at the variable living environment was negative, which means that the larger the area from which the family leader originates, the less likely it is that his 
family needs institutional assistance ${ }^{13}$. This result demonstrates more difficult access for rural and small-town families to institutions providing assistance to individuals and families in crisis, as well as the incompetence of their leaders in managing family resources, coping in difficult situations and low social competences.

2) In the models of demand for assistance of a Voluntary Service Centre and UP, the likelihood of the family leader's need for assistance of these institutions by the families managed by them increases with age. In contrast, the probability of using the assistance of a P-P Clinic decreases with age.

3) In all models, the probability of applying for institutional assistance in the group of problem families increases along with the level of education of their leaders ${ }^{14}$, which is associated with their more frequent undertaking of task strategies to cope with a crisis and a higher level of social competences conditioning effectiveness in the search for social support (compared to leaders that have a lower level of education).

4) Only in the model of demand for assistance of a P-P Clinic, the parameter at the variable income is statistically significant. The higher the income declared by the leader of a problem family, the more he is willing to take advantage of this form of assistance. It should be emphasized that concluding the causes of this trend is difficult due to the declarative nature of obtaining data.

Generally speaking, the jointly considered sets of variables generally describe well the needs of problem families for institutional assistance. This is evidenced by the significant at the level 0.05 statistical values $\chi^{2}$ in OPS, P-P Clinic and Voluntary Service Centre models ${ }^{15}$. The accuracy of conclusions based on the estimated models ranges from 53.3 to $61.9 \%$.

After applying the procedure from the general to the specific, optimal models of demand of problem families for institutional assistance were yielded. In accordance with the adopted methodology, these models are characterized by all significant parameters (insignificance of absolute terms were allowed). It is worth emphasizing the fact that the symbols of parameters in optimal models are the same as the symbols of corresponding parameters in models with all variables. The results obtained tend to formulate the following conclusions:

1) The probability of applying for assistance from the OPS is the greater, the more educated the respondent, and the smaller the town he lives in.

2) Better educated and young leaders of problem families are more likely to take advantage of individual and family therapy in a P-P Clinic than older and less educated leaders. This is probably the result of the occurrence of educational difficulties and problems arising from the adolescence period of teenage children living in families led by young and middle-aged leaders, having greater knowledge in the field of health education and health promotion, and a higher level of social competences determining the effectiveness of seeking social assistance and support.

3) The probability of applying for help of a Voluntary Service Centre is the greater, the older the respondent.

4) It was failed to build a model of demand for assistance of UP with significant parameters at the significance level of 0.05 (except the absolute term). In the model with the variable age the parameter for this variable is significant at the level of 0.1 .

5) Also, in the model of general demand for assistance the parameters at the variables living environment and education are significant only at the level of 0.1 . In none of the optimal models did income occur as a significant explanatory variable.

\footnotetext{
13 This result, however, is burdened by the insignificance of parameters with the living environment variable in the model of demand for the assistance of a P-P Clinic, a Voluntary Service Centre and UP. In the case of needing assistance of an OPS and assistance in general (without indicating the type of institution) the parameters with this variable are significant only at the level 0.1 .

${ }^{14}$ In the models of demand for assistance of an OPS, P-P Clinic and Voluntary Service Centre, the parameters at the variable education are significant at the level 0.05 , and in the model of demand for assistance of PUP at the level 0.1. The parameter at the variable education in the model of demand for assistance in general is insignificant.

${ }^{15}$ Low values of the pseudo determination coefficient R2 are often observed in logit models that describe social phenomena, in: M. Gruszczyński, Modele i prognozy zmiennych..., op.cit.
} 


\section{- STIMULATION OF CHANGES IN DEMAND OF PROBLEM FAMILIES FOR INSTITUTIONAL ASSISTANCE}

The estimated models allow to simulate the probability of the demand of problem families for institutional help, depending on changes in the explanatory variables. An example is the model of demand of problem families for OPS assistance, drawn up depending on their age, education and living environment. The probability of the demand for OPS assistance increases with the age of the family leader, his education and the smaller the place of residence of the family led by him. Therefore, if the probability that such assistance will be needed by a problem family leader from a medium-sized city, with primary education, who is 25 years old is only 0.23 (of 100 people with these characteristics, 23 people expect assistance), then the probability for a person who is 75 years old living in the countryside, with tertiary education is as high as 0.85 . On the other hand, the model of demand of problem families for the assistance of a P-P Clinic was drawn up depending on their age, education and income. The likelihood of using the assistance of a P-P Clinic in the future increases the younger, better educated and wealthier their leaders are. Therefore, if the probability that such assistance will be needed by a person who is 75 years old with primary education and an income (for 1 person in the family) at the level of the 1 st percentile $(0.204$ thousand PLN) is only 0.07 , then the probability for a person who is 25 years old with tertiary education, with an income at the 9th percentile (1.00 thousand PLN) is 0.79 .

\subsubsection{MODELS OF DEMAND OF PROBLEM-FREE FAMILIES FOR INSTITUTIONAL ASSISTANCE}

Like in the case of leaders of problem families, also for leaders of problem-free families, the $t$-Student test showed that depending on the institution, different variables significantly discriminate the studied population. In the case of the need for assistance of OPS it is the place of residence, age and education, and the larger the city, the older and less educated the people, the higher the probability of applying for institutional assistance. In the case of a P-P Clinic, the place of residence and age significantly discriminate the surveyed population - the larger the city, and the younger the leader, the greater the need for assistance from this institution. In the case of the need for assistance of a Voluntary Service Centre only the education variable was statistically significant, while the less educated the leaders of problem-free families are, the greater their need for the help of volunteers. Education is the only variable significantly discriminating the population of respondents from problem-free families in the scope of needing assistance from UP. Assistance in the scope of employment or retraining is usually expected by people with a lower education.

The explanatory variables - place of residence and age - significantly determine the surveyed population in terms of expectations for assistance from at least one of the institutions (total) - the larger the place of residence where problem-free families live, and the older their leaders, the higher the demand for institutional assistance. Also in models of demand for assistance reported by leaders of problem-free families, various sets of variables depending on the type of institution proved significant. However, even here there are certain similarities:

1) The demand for institutional assistance increases with the size of the town where the problemfree family lives.

2) The older the leader of this type of family, the less likely that he will take advantage of assistance from a P-P Clinic, Voluntary Service Centre and PUP, while in the case of the two latter institutions, the strength of this correlation is much weaker due to the insignificance of the parameter. A different situation exists in the case of need for assistance of OPS: here the older the leader of a problem-free family, the greater the probability of using social assistance.

3) The probability of applying for institutional assistance decreases with the level of education of leaders coping with problems ${ }^{16}$.

\footnotetext{
${ }^{16}$ Only in models of demand for assistance of PUP and in general, the parameters at the variable education are statistically significant at the level 0.05 .
} 
4) The higher the income of the problem-free family leader, the less interested he is with institutional assistance. This correlation is particularly strong in the case of the need for assistance of OPS and P-P Clinic (parameters significant at the level of 0.05) and much weaker in the case of the remaining institutions (parameters statistically insignificant).

5) Only in the model describing the need for assistance of a Volunteer Center the value $\chi^{2}$ was not significant at the level of 0.05 . The significance of this statistic in other models means that the sets of four variables found in them significantly describe the need of problem-free families for institutional assistance ${ }^{17}$.

The accuracy of conclusions based on the estimated models ranges from 53.7 to $64.9 \%$. According to the methodology, optimal models of demand of problem-free families for institutional assistance are characterized by all statistically significant parameters (insignificance of absolute terms was allowed):

1) The probability of applying for assistance of OPS is greater, the larger the town where the respondent comes from, the older he is and the lower the income he has at his disposal.

2) The probability of applying for assistance in a P-P Clinic is greater, the larger the place of residence of the family and the older its leader is.

3) It was failed to build a model of demand for assistance of a Voluntary Service Centre with parameters significant at the level of $0.05^{18}$.

4) In the best model describing the demand for assistance of UP there is only one variable, education - the higher the education held by the leader of a problem-free family, the less likely it is that he will expect assistance from a UP.

5) In the model of demand for assistance in general, the parameter with the variable place of residence is significant and positive - the smaller the town where the family lives, the greater the probability of using institutional assistance. In contrast, the older and better educated the leader, the less likely it is that he will expect institutional assistance in a situation of family crisis.

\section{- STIMULATION OF CHANGES IN DEMAND OF PROBLEM-FREE FAMILIES FOR INSTITUTIONAL ASSISTANCE}

For the purposes of the simulation, models were estimated for problem-free families with the same variables as for problem families. The model of demand of problem-free families for OPS assistance was drawn up depending on the place of residence, age and education of their leaders ${ }^{19}$. The probability of reporting the need for assistance of OPS increases along with the size of the town where the family lives, the age of the family leader and is higher the lower his level of education is. If the probability that such assistance will be needed by a person living in the countryside, having higher education and who is 25 years old is only 0.06 , then the probability for a person who is 75 years old from a middle-sized city, with primary education amounts to 0.76 .

The model of demand of problem-free families for assistance of a P-P Clinic was built depending on their age, education and income. The quality of this model is much worse than the corresponding model for problem families (coefficient of pseudo R 2 determination is three times lower). Due to the poor results of estimation of this model, an optimal model of demand for assistance of a P-P Clinic was assumed, consisting of three variables: place of residence, age and income. According to this model, the probability of the need of problem-free families for the assistance of a P-P Clinic is higher the younger the family leader is, and the larger the town where he lives, and the smaller the income he has at his disposal. The quotient of parameters at the variables income and age is 26.2 , which means that the reaction of probability on income growth by 1.0 thousand PLN is more than 26 times greater than the reaction of probability on the increase of

\footnotetext{
${ }^{17}$ The values of the pseudo determination coefficient R2 are low and range from 0.0136 (Voluntary Centre) do 0.0712 (OPS).

${ }^{18}$ In the model with the place of residence as the only explanatory variable, the parameter with it was positive and significant at the level 0.0870 .

${ }^{19}$ In this model, the significance level of the parameter at the variable education (0.0621) slightly exceeds the criterion adopted in this study (0.05), but this variable was maintained due to the need for comparisons with the model for problem families.
} 
age by 1 year $^{20}$. According to the estimated model of probability of reporting demand for assistance of a P-P Clinic by a leader of a problem-free family who is 25 years old, living in a medium-sized city and having income at the level of the 1 st percentile ( 0.5 thousand PLN) is 0.83 . On the other hand, the probability of reporting demand for assistance of a P-P Clinic by a leader of a problemfree family who is 75 years old, lives in the countryside and has a an income at the level of the 9th percentile (1.2 thousand PLN) is 0.08 .

\subsubsection{MODELS ESTIMATED FOR COMBINED DATA ABOUT LEADERS FROM PROBLEM AND PROBLEM-FREE FAMILIES}

The conducted $t$-Student test of significance of differences of mean values of potential explanatory variables indicates that the variables environment of residence and age do not differentiate significantly in both studied groups. Leaders of problem-free families are much better educated and have higher incomes at their disposal than their counterparts from problem families. In contrast, the $t$-Student test of significance of differences in mean values of responses concerning the need for assistance (or lack thereof) indicates that, in addition to the assistance of a P-P Clinic, leaders of problem families foresee the necessity to use institutional assistance more frequently in the future than leaders of problem-free families. In the estimated models of demand of respondents in general (without division into groups), in addition to the assistance of a Voluntary Service Centre, the variable problem proved statistically significant. The ability to explain the problem variable was so strong that the optimal models did not include the variables education and income ${ }^{21}$. In all optimal models, the variable age was also statistically significant. In order to identify differences in the changes of probability of demand of problem and problem-free families for institutional assistance, additional models were estimated for the P-P Clinic and Voluntary Service Centre in terms of the variables age and problem $^{22}$. For institutions OPS and UP, the models of demand for assistance in terms of age and the problem variable proved optimal.

Analysis of the four estimated models leads to the following conclusions:

With the age of family leaders, the probability of the family seeking assistance of the OPS, Voluntary Service Centre and UP increases. The probability of applying for the assistance of OPS and UP by a 75 -year-old person is from 0.26 to 0.29 higher, depending on the institution and the status of the family, than by a 25 -year-old person. The probability of applying for the assistance of a Voluntary Service Centre by a 75 -year-old person is only 0.08 higher than by a 25 -year-old person. In contrast, the probability of applying for the assistance of a P-P Clinic decreases with age, and this decrease is very fast. The probability of applying for the assistance of a P-P Clinic by a 75-year-old person is as much as 0.48 for respondents from problem-free families and by 0.49 for problem families lower than by a 25 -year-old person.

The probability of applying for institutional assistance by the leaders of problem families is for each age group higher compared with leaders of problem-free families, although the differences of these probabilities depend on the type of institution indicated by them. This difference in the age group 25-75 years old is only symbolically greater (by 0.01) in the case of P-P Clinics. In the case of the Voluntary Service Centre, the probability of applying for the assistance of this institution by leaders of problem families is (in the age group 25-75 years old) higher than for problem-free family leaders by 0.27 . For OPS, depending on the age group, this difference amounts from 0.13 to 0.16 , while for UP from 0.10 to $0.11^{23}$.

\footnotetext{
${ }^{20}$ Easier interpretation occurs when we express income in hundreds of Zlotys. Then the reaction of probability on income growth by one hundred Zlotys is more than 2.6 times greater than the reaction of probability on the increase of age by 1 year.

${ }^{21}$ The problem variable is "representative" of both these variables, because as the t-Student test shows, they also demonstrate significantly different values for problem and problem-free families.

${ }_{22}$ These are not models that are optimal in terms of the insignificance of certain parameters, but necessary for reasons of comparability.

${ }^{23}$ Of course, along with a further increase in age, in accordance with the logic of the logistic curve, these differences will decrease to almost complete disappearance, but this may occur for such values of age, which in reality do not exist.
} 


\section{CONCLUSIONS AND RECOMMENDATIONS}

To estimate the demand of problem families for institutional assistance, the statistical method was used, in which the subject of modeling is the probability of occurrence of the analyzed phenomenon. Models of demand of problem families for institutional assistance differ from models of demand of problem-free families both in terms of anticipated general trends, and the anticipated use of social services of specific support institutions. These differences arise from the values of the estimated parameters, and are also the result of a different impact of some variables on articulating the need for obtaining assistance. In light of the study results, one can conclude the expected demand of family leaders (from both groups) for institutional assistance:

1) In terms of the total demand for institutional assistance a trend was noted of the increase of interest in it of problem families, along with the increase of the size of their place of residence. On the other hand, the worries of families currently dealing with problems in relation to the needs of using institutional assistance in the future are greater, the smaller their place of residence.

2) With regard to individual assistance institutions, a reverse trend was noted - the smaller the place of residence of the family, the stronger the tendency for using services offered by specific institutions (aside from labor offices). This indicates the presence of a higher risk of marginalization and social exclusion in small areas (villages and small towns), as well as their dealing with a greater number of problems when compared to families living in medium-sized cities. It can be assumed, therefore, that in families living in smaller towns there is a greater severity of crisis symptoms.. Families currently dealing with problems, especially those who live in larger areas (small and medium-sized cities) are burdened by a high probability of the occurrence of a complex crisis. This indicates a strong trend in the leaders of this type of family articulating potential needs associated with the sphere of social assistance, psychologicaleducational and voluntary support. The phenomenon of unemployment to a lesser extent affects families living in medium-sized cities, than rural and small-town families. The possibility of the emergence of real threat of the family with unemployment in the future are often declared by leaders of families from small towns, but mostly by leaders of rural families, which may indicate the intensified, negative tendency to a decrease in the level of employment in small areas (village and small town). In contrast, the threat of unemployment for families living in a medium-sized city and currently dealing with problems seems to be even less felt by their leaders, as indicated by the distribution of obtained trends.

The use of logit models in studies on family enable to study large populations of various types of families in a short time and determine the developmental trends of these phenomena and processes, which significantly affect their current and potential functioning. The use of the discussed statistical procedure, however, does not mean the abandonment of qualitative studies, which are invaluable in individual diagnosis, as well as extremely useful in establishing and identifying the social contexts that determine risk of crisis. According to canons of modern methodology of social studies, a reliable diagnosis and prognosis should take account of the complementary use of qualitative and quantitative research methods and techniques.

The statistical method presented in this article has not yet been used in the detailed diagnosis and prognosis of phenomena in the area of social rehabilitation, social readaptation and reintegration of social misfits. The application of logit models in pedagogical empirical procedures may be extremely useful in diagnosing phenomena characterized by high dynamics and complexity of the sources of their occurrence, as well as requiring rapid social response - drawing up precise prognoses, designing remedial strategies and their implementation. This method can also be useful in monitoring the course of socialization, education and training processes, as well as supporting social disadvantaged individuals and socially. Among others, it can be used in studies on the educational market or civic activity. It can also be invaluable in developing and forecasting directions of development of various types of educational institutions or institutions providing social assistance and support, as well as in predicting the probability of occurrence of certain phenomena and trends in the area of criminality and social maladjustment of children and 
adolescents. To conclude, the proposed statistical method (logit modeling) can provide an analytical database enriching, and also complementing methods of measurement, which are already recognized and successfully used in social and educational studies.

\section{References}

[1] Gruszczyński M., Modele i prognozy zmiennych jakościowych $w$ finansach $i$ bankowości, „Monografie i Opracowania SGH” 2001, no. 490.

[2] James R.K., Gilliland B.E., Strategie interwencji kryzysowej, PARPA, Warsaw 2009.

[3] Kowerski M., Assessment of the economic condition of small enterprises with logit micromacro models, Conference on Human System Interaction, HSI08, WSiZ, IEEE Industrial Electronics Society, Kraków, 2008.

[4] Kowerski M., Prognozowanie zjawisk dyskretnych, [in:] E. Nowak (red.), Prognozowanie gospodarcze, AWP Placet, Warsaw 1988.

[5] Lis-Turlejska M., Psychologiczne konsekwencje traumatycznego stresu - współczesne kierunki badań, „Nowiny Psychologiczne” 2000, no. 2.

[6] Nowak B.M., Rodzina w kryzysie. Studium resocjalizacyjne, PWN, Warsaw 2011. 